\title{
LA EMIGRACIÓN A FRANCIA (SEGUNDA MITAD DEL SIGLO XX). UNAS REFLEXIONES SOBRE RETORNOS Y REINTEGRACIONES
}

\author{
por \\ Rose DuRoux \\ Université Blaise Pascal, Clermont-Ferrand
}

RESUMEN: El estudio se centra en el emigrante español a Europa -a Francia más particularmente. Quedan fuera de él la migración estacional y el exilio. El ángulo de observación es el retorno. Más que de un balance historiográfico se trata de abrir pistas. Las vertientes para la investigación futura son múltiples: el lugar adonde se vuelve; las redes del regreso; las escisiones familiares, generacionales, culturales, etc., pero lo que aquí se privilegia es el papel de las políticas migratorias, del asociacionismo y de los medios de comunicación para mantener al emigrante dentro del marco nacional. Desde 1956 hasta boy, la preocupación por el retorno ha variado: retorno de las divisas, de los bombres, de los votos... Hoy las autonomías son las que van tomando en cuenta las aspiraciones a la vuelta y a la readaptación «indolora» (doméstica, social y cultural). El retorno actual, más importante de lo previsto, se produce en una España que se ha vuelto país de inmigración.

Palabras Clave: Emigración a Europa. Siglo XX. Políticas migratorias. Retorno de las divisas, de los votos, de los emigrantes. Asociacionismo. Señas de identidad y literatura.

ABSTRACT: This article focuses on Spanish emigrants to Europe, and to France in particular. Seasonal migration and exile are beyond the scope of this study. The subject is instead approached through the notion of return. More than a bistorical resume, the aim is to open avenues of inquiry. The paths for future research are many: the choice of places to which to return, the networks for return, the fragmentation of families, generations, cultures, etc. What has been chosen as the centre of this analysis is the role of migration politics, associations and the media in order to maintain the migrant in the national framework. From 1956 until now, the reasons for concern with return bave been different: the return of currencies, of men, of votes. Today it is the autonomías (regions) that are taking into account the 
desire to come back and the desire for a smooth re-adaptation (domestic, social and cultural). Current return, more important than bad been foreseen, occurs in a Spain that has become a country of immigration.

KEY WORDS: Emigration to Europe. Migration policies. Currencies. Votes. Migrants. Associations. National identity.

\begin{abstract}
«La decisión de cargar los muebles es un momento clave. Lo has soñado durante años, cada vez que has ido de vacaciones. Te lo has imaginado de mil maneras, pero nunca te has decidido. Has dejado que el tiempo transcurriera y que fuera tomando las decisiones por ti. Pero el empujón definitivo tienes que darlo tú. Y cuando has cargado el camión, y ves que se pone en marcha, por un lado sientes cierto alivio, pero por otro un indiscutible sudor, el que te hace saber que la cosa va en serio, y que la marcha atrás será difícil».

Juan Tortosa, «La segunda emigración», El País, 12-4-1998
\end{abstract}

Mi intención es observar al emigrante español de la segunda mitad del siglo XX. El «emigrante» es por definición «el que se traslada de su propio país a otro, generalmente con el fin de trabajar en él de manera estable o temporal» (DRAE, subrayado mío). Queda pues fuera de este estudio el exiliado. Se excluirá además la migración estacional (de los «temporeros» a Francia, Bélgica o Suiza por ejemplo), para observar solamente a los más estables, es decir a los que han permanecido en el extranjero tres años o más (tres años es, como se verá, un criterio corriente). El ángulo de observación privilegiado será el retorno, por lo cual voy a acudir necesariamente al vocablo migración.

Se sabe que la «migración laboral» procede por un sistema reticular compuesto de micro-conexiones tanto a la ida como a la vuelta. Sin embargo el fenómeno del retorno es más borroso y las vertientes para la investigación futura son múltiples: el lugar al cual se vuelve; las redes del regreso; la escisión familiar del volver; el papel del cónyuge y de la segunda generación en el regreso; el choque cultural del retornado; las incidencias sobre la sociedad de origen; la marginación; el cambio de valores; el ahorro y las inversiones en el país de origen; y, claro está, el papel de las políticas migratorias, del asociacionismo y de los medios de comunicación para mantener al emigrante dentro del marco nacional y contrarrestar la «desafiliación». De estos temas fecundos voy a privilegiar, para estas reflexiones, los tres últimos, considerados por A. Izquierdo Escribano y G. Álvarez Silvar ${ }^{1}$ como poco atendidos: las políticas mi-

1 IZQuierdo Escribano, A. y Álvarez Silvar, G. (coords.): Políticas de retorno de emigrantes, Universidade da A Coruña, Servicio de Publicaciones, 1997 («Presentación», pp. 5-7; «Estado actual de la investigación sobre el retorno», pp. 45-57). Tipología: BOVENKERK, F.: The sociology of return migration: A Bibliographic Essay, La Haya, M. Nijhoff, 1974. CESARE, F. P.: «Migration and social change: expectations and reality. A case study of return migration from the United States to

Hispania, LXII/2, núm. 211 (2002) 577-596 
gratorias y asociacionistas así como el papel de los medios de comunicación, en el sentido cultural más amplio, es decir desde la prensa hasta la literatura a las que dedicaré una atènción particular. Limitaré en lo posible la observación a las últimas décadas del siglo XX y a Europa, centrándome en Francia esencialmente, pero siempre con un espíritu comparatista para un mejor entendimiento de la «migración laboral», como sujeto y objeto de socio-historia² ${ }^{2}$.

\section{BREVE MARCO CRONOLÓGICO}

La emigración laboral a Francia del siglo XX no es un hecho nuevo, según nos informan Juan Bautista Vilar y María José Vilar ${ }^{3}$ : es ignorado todo un flujo de braceros gallegos, extremeños y andaluces del siglo XIX que abrieron caminos en la geografía francesa. Pero, indudablemente, la guerra de 1914-1918, con la subsiguiente penuria de brazos, funcionó como un acelerador ${ }^{4}$ : el flujo se intensifica entonces, pasando la colonia de unos 80.000 emigrantes en 1900 a más de 300.000 en el periodo de entreguerras. El núcleo más numeroso de expatriados lo constituyen los levantinos que se dirigen hacia Provenza y valle del Ródano. Al advenimiento de la República, la emigración laboral alcanza su cota más elevada (352.000) pero es seguida por un descenso en 1936 y por un corte posteriormente; sólo se reanuda en el quinquenio 1956-1960 hasta generar el grupo extranjero más numeroso en 1968: más de 600.000.

Lo nuevo de la segunda mitad del siglo XX es lo masivo de la emigración a la Europa industrializada cuando se anula el atractivo americano y se acelera la atracción ultrapirenaica. El «boom» de la emigración española en los años sesenta coincide con el desarrollo de los países vecinos ávidos de mano de obra tras los años de reconstrucción que siguieron la Segunda Guerra Mundial (les 30 Glorieuses). Un campesinado y un peonaje «emigrantes» buscan colocación en las faenas descuidadas por los europeos del norte. Esta emigración le viene muy bien a la España del éxodo rural y del salario escaso.

Es evidente que, a partir de 1960, Alemania y Suiza, por su mayor nivel salarial y su moneda fuerte, han tomado el relevo de los países latinoamericanos;

Southern Italy", en International Migration Review, $\mathrm{n}^{\circ}$ 8, 1974, pp. 245-262. WyMAN, M.: Roundtrip to America. The immigrants return to Europ 1880-1930, Ithaca, Cornell University Press, 1993. DUBET, F.: Immigrations: qu'en savons-nous? Un bilan des connaissances, Paris, La Documentation française, 1989. Duroux, R. y MONTANDON, A. (eds.): L'émigration: le retour, Clermont-Ferrand, Presses Universitaries Blaise Pascal, Cahiers du CRLMC, 1999. MARTÍnEZ VEIGA, U. (dir.): Situaciones de exclusión de los emigrantes españoles ancianos en Europa, Editado por FACEEF, Fundación $1^{\circ}$ de Mayo et alii, París, 2000.

2 Fuentes de archivo: Les Étrangers en France. Guide des sources d'archives publiques et privées XIXe-XXe siècles, Paris, Co-ed. Génériques-Direction des Archives de France, 1999, 3 vols., 2.408 págs. Guías del retorno, Madrid, Ministerio de Trabajo y Asuntos Sociales, desde 1994.

3 Vilar, J. B. y Vilar, M. J.: La emigración española a Europa, Madrid, Arco Libros, 1999.

4 NADAL, J.: La población española (siglos XVI a XX), Barcelona, Ariel, 1976, $4^{\mathrm{a}}$ ed., pp. 209-ss. 
se ve nítidamente el cambio de rumbo en la emigración de los gallegos, por ejemplo. El área de salida es amplia: gallegos, andaluces, extremeños, valencianos, murcianos y algunos asturianos y leoneses. En cuanto al área receptora también se va extendiendo: Reino Unido, Holanda, Bélgica, Luxemburgo, Dinamarca, Suecia e incluso Italia y Portugal. Durante el decenio de los 60, nos dice Jordi Nadal, sale un millón y medio de personas - «una cifra sin precedentes en los anales emigratorios españoles" 5 -, con remesas de dinero estimadas en cerca de 2.500 millones de dólares USA, entre 1960 y 1969, sin contar los ahorros que se llevaban personalmente. Entre los rasgos demográficos del contingente considerado destacan -esquematizando excesivamente - una edad entre 15 y 55 años, una ausencia media de tres años, una fuerte nupcialidad si bien tardía. Entre 1960 y 1973, la emigración llega a afectar, finalmente, a más de 2 millones de personas, cifra muy importante habida cuenta que en 1970 la población activa es de 12 millones de personas; 1973 marca el punto de inflexión en la historia de la población española: España deja de ser un país de emigración externa. Añadido al fenómeno concomitante del turismo, el retorno es un factor de europeización progresiva.

\section{INTERACCIONES EMIGRACIÓN-EXILIO}

A pesar de las interacciones insoslayables he desvinculado, hasta aquí, a la emigración del exilio. Ciertos vínculos, bien es verdad, son poco visibles. A menudo para captarlos se necesitan proyecciones de luz lateral. Valga un primer enfoque: Jorge Semprún preguntado acerca de la percepción de los españoles en Francia (El País, 12 de abril 1998: « ¿La solidaridad francesa con los inmigrantes españoles fue mayor que el rechazo?») opina lo siguiente: «El papel de los republicanos quedó marcado, sobre todo, a partir de su masiva incorporación a la Resistencia francesa contra los nazis. [...] La solidaridad en los combates y en la cárcel creó lazos muy fuertes y construyó una especie de prejuicio favorable a los españoles, que le vino muy bien a la posterior inmigración económica». He aquí otro flash, sacado del estudio de Frédéric Serralta, "Juan Mateu

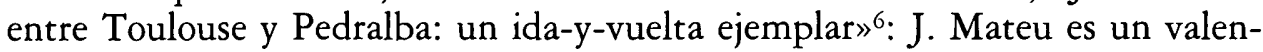
ciano que emigra a finales de los años 50 para trabajar de albañil en Toulouse - foco «republicano» bien conocido- y hace un clásico retorno económico a su tierra valenciana, pero ya con preocupaciones sociales que expresa mediante la afición al teatro desarrollada en la emigración. Los trabajos de Geneviève Dreyfus-Armand arrojan una luz nueva: según su muestreo de españoles en zonas agrícolas, industriales y mineras (en torno a Toulouse, Cahors, Decazeville y

5 Ibid., pp. 220-224.

6 CUESTA, J. (coord.): El retorno. De exilios y migraciones, Madrid, Fundación F. Largo Caballero, 1999.

Hispania, LXII/2, núm. 211 (2002) 577-596 
Saint-Denis), aparece que el encuentro de los exiliados y de los emigrantes depende en gran parte del entorno, con vínculos evidentes entre las gentes de la mina y de la fábrica (matrimonios) y casi invisibles en el entorno agrícola ${ }^{7}$.

Se podrían multiplicar los ejemplos de la interacción y de las maneras de enfocarla. Sin embargo, si no deben obviarse las confluencias tampoco se pueden negar las incomprensiones. Guy Hermet, durante los años 60, a partir de testimonios directos, observaba los desencuentros: «Bien qu'elle soit regrettable, l'hostilité d'une minorité de réfugiés politiques à l'égard de leurs compatriotes immigrés récemment s'explique pour plusieurs raisons. La première tient à l'échec réel des tentatives de rapprochement et de soutien des immigrants récents effectuées par les réfugiés politiques il y a quelques années. Très marqués par la propagande et les pressions du gouvernement actuel de l'Espagne, ces immigrants ont considéré les efforts des républicains en leur faveur avec la plus grande défiance. Il faut tenir compte également de ces deux catégories d'Espagnols, les réfugiés étant généralement plus âgés que les immigrants économiques, et ne pas oublier que les républicains ont des origines sociales plus bourgeoises que celles des travailleurs qui viennent aujourd'hui en France» ${ }^{8}$.

La historia origina, continuamente, estratos de «económicos» y de "políticos» más o menos compatibles. La colonia preexistente, en principio hostil a la llegada del contingente nuevo, modifica a veces su postura por un movimiento reflejo de "paisanaje»?. En palabras de José Babiano, la diferenciación social es muy relativa y obviar la historia sociocultural de «los económicos» es producto de diversos prejuicios: «son dignas de atención las estrategias domésticas, no son una mercancía sino sujetos históricos activos» ${ }^{10}$. Desde luego, en lo tocante al retorno, que es de lo que aquí se trata, es obvio que, aunque para el desplazado voluntario la separación tiene un límite temporal definible y para el desplazado forzado este límite es indefinible, uno y otro deberán pasar por las mismas etapas de readaptación doméstica, social y cultural («Veinte años de ausencia o de exilio ique más da!», Alfonso Costafreda) ${ }^{11}$.

7 DReYfus-ARmand, G.: El exilio de los republicanos españoles en Francia. De la guerra civil a la muerte de Franco, Barcelona, Crítica, 2000.

8 Hermet, G.: Les Espagnols en France, Immigration et culture, París, Les Éditions Ouvrières, 1967, p. 223, nota 41 .

9 Buen ejemplo de solidaridad lo ofreció la colonia de emigrantes de Béziers en 1939.

10 BABIANO, J. y FERNÁNDEZ ASPERILlA, A.: «El asociacionismo como estrategia cultural: los emigrantes españoles en Francia, (1956-1974)", en Documentos de trabajo de la Fundación $1^{\circ}$ de Mayo, Doc 3/1998, Madrid, p. 6. Catani, M. y PALlida, S. (eds.): «Le rôle du mouvement associatif dans l'évolution des communautés immigrées", en Rapport FAS/DPM, 2 vols., febrero de 1987: a mediados de los 80 , la comunidad italiana y la española tienen, respectivamente, unas 350 y 380 asociaciones; la portuguesa 900 , con 70.000 socios.

11 Grinberg, L. y R.: Psychanalyse du migrant et de l'exilé, Lyon, Césura, 1986. Clavería PraDA, M. C.: «Procesos psicológicos de retorno», en Políticas del retorno..., op. cit., pp. 75-77. La cita es un verso de A. Costafreda, exiliado en Ginebra en donde murió. 


\section{POLÍTICAS DE RETORNO Y ASOCIACIONISMO}

El retorno como la emigración puede ser una aventura (o desventura) meramente privada, pero, por lo general, el grupo y el Estado influyen. Opina Nicolás Sánchez-Albornoz que, «según las épocas, el gobierno prohibe la emigración o procura encauzarla hacia determinados destinos. En otras, la salida es libre o, incluso, se avala o se fomenta». Esta última opción es la de España en los años 1956-1973: fomentar. En efecto, crea el Instituto Español de Emigración, en 1956, no sólo para organizar las salidas manteniéndolas dentro del marco nacional sino también para alentarlas. Sus prioridades son entonces garantizar el retorno de divisas y aliviar las tensiones sociales ${ }^{12}$. Cuando irremediablemente la corriente se invierte, el Estado debe arrostrar el retorno. Lo hará progresivamente, primero de manera puntual y algo rezagada, y, a partir de 1978, de modo cada vez más afirmado, sistemático, transparente.

Además el gobierno español ha sabido utilizar la infraestructura de las asociaciones de emigrantes existentes en el extranjero. Lo cual no significa que todas las iniciativas procedan del Estado; muchas emanan de los mismos socios, los «usuarios». Las asociaciones son un modo de hacer oir su voz, pues además de ser una reserva de señas de identidad constituyen una tribuna para la defensa de los intereses. Pero no cabe duda de que son una correa de transmisión entre el emigrante y el gobierno; y viceversa: algunas fueron fomentadas desde arriba durante el franquismo y siguen siendo para el gobierno y para los partidos una vía de penetración y de influencia.

El asociacionismo merecería una investigación global, como mínimo a escala europea; en espera de esa síntesis, se puede afirmar que, en lo que concierne al retorno, el mayor elemento de cohesión de las asociaciones es la voluntad de preservar la posibilidad de volver. Si hay miles de asociaciones fuera de España va habiendo cada día más dentro de ella, dado el número de los retornados proclives a reagruparse, porque el retorno también crea necesidades concretas e inconcretas. ¿Lo concreto? Una directriz de todo el discurso asociacionista es la reivindicación de las "pensiones", sujetas a todo un aparato legislativo complejo en el ámbito europeo, más o menos flexible: las pensiones que se cobran en el extranjero por un trabajo efectuado en España, las que se cobran en España tras la repatriación por una actividad en otro país, sin contar las que se han adquirido en una «emigración circular» por varios países. También es recurrente la demanda sanitaria. Convendría hacer una periodización pormenorizada pues, al transcurrir el tiempo, las prioridades evolucionan. Estos últimos años, por ejemplo, emerge el afán cultural; tal vez sea porque las pensiones ya van tomado un cauce normalizado tranquilizador, por lo menos en la Comunidad europea.

12 SÁnCheZ-AlbornOz, N.: Españoles hacia América, La emigración en masa 1880-1930, Madrid, Alianza América, 1988, p. 18.

Hispania, LXII/2, núm. 211 (2002) 577-596 
La tendencia de las asociaciones locales es reagruparse en federaciones para ser más eficaces alcanzando una envergadura, regional, nacional e incluso internacional. Voy a citar solamente unas cuantas federaciones con empuje a diferentes niveles (pero hay muchas más).

1) Federaciones internacionales. Unas federaciones, que se podrían calificar de «sin fronteras», tienen su sede en el extranjero, como la «Confederación Europea de Asociaciones Españolas de Padres de Familia», cuyo primer foco importante fue Alemania, y la «Coordinadora Europea de Asociaciones de Emigrantes Europeos», que se creó oficialmente en Bruselas en 1977 pero que existía anteriormente puesto que ya en 1974 reclamaba precisamente una Ley del retorno: «En la actualidad, la Coordinadora Europea representa a 9 Federaciones nacionales distribuidas en 8 países de la Unión Europea; suman alrededor de 450 organizaciones de base, y el número aproximado de socios asciende a unos 53.000». Con la crisis económica generalizada de los 70, la defensa de los intereses se hace más incisiva: «iDe Alemania nos echan y en España no nos quieren! ${ }^{13}$.

2) Federaciones nacionales. Me detendré en un caso «nacional»: el de FAEEF (Federación de Asociaciones de Emigrantes Españoles en Francia), que ha sido estudiada de manera modélica por José Babiano y Ana Fernández Asperilla ${ }^{14}$, en la que destacan las redes levantinas, andaluzas y gallego-leonesas. La importancia de la Federación en Francia tiene que ver con la demografía: el censo francés de 1962 computaba 442.000 españoles; el de 1968, 607.000 [entre ellos 70.000 refugiados]; el de 1975, 497.000. A estas cifras, debe añadirse que, entre 1946 y 1975, habían adquirido la nacionalidad francesa alrededor de 40.000 españoles. De ahí que se teja una red federativa densa, regida por la ley francesa de 1901 como apolítica; en realidad, la respalda la

13 García Tejedor, A. y Tiscar Astasio, R.: Políticas de retorno..., op. cit., pp. 239-250. BORDERÍAS URIBEONDO, M. P.: «La emigración española a Europa a lo largo del siglo XIX», en $A$ Distancia, vol. 18, $\mathrm{n}^{\circ} 1$ (junio 2000), pp. 209-216: los convenios bilaterales (hispano-alemán, 1960, hispano-suizo 1961, etc.) después de impulsar la emigración impulsan el retorno. Vid. LEBON, A. y ZAMORA, F.: "Combien d'étrangers ont quitté la France entre 1975 et 1982?», en Revue Européenne des Migrations Internationales, sept. 1985; evalúan en 75.000 el número anual de salidas en 19751982; los españoles suman más de 8 retornos para 1 llegada; muchos aceptan la allocation-retour de reinserción en España -el famoso million Stoléru- o sea 10.000 F. Entre los 94.000 "retornosreinserción", de 1977 a 1981, había: $39 \%$ portugueses, $25,4 \%$ españoles, $8 \%$ tunecinos, $6 \%$ marroquíes y $3,7 \%$ argelinos. Francia (después de Alemania) abandonó este tipo de política costosa ya que no incitaba al retorno a la población... «indeseable».

14 Babiano, J. y Fernández AsPerilla, A.: op. cit., pp. 1-42. La FAEEF fusionó con la APFEEF (Asociación de Padres de Familias Españolas Emigrantes en Francia) en noviembre de 1991, dando nacimiento a la FACEEF (Federación de Asociaciones y Centros de Emigrantes Españoles); votaron 101 asociaciones. La FACEEF reúne 185 centros, la mitad de ellos sitos en île-de-France. 
embajada, la financia el IEE, la ayudan las Misiones Católicas. A través de la FAEEF, la Administración franquista, «retroalimentando el mito del retorno», incentivaba el envío de divisas a España, la inversión en la vivienda, y obraba en cuatro ámbitos: asistencial; educativo (infancia, $2^{a}$ generación, becas para venir a estudiar a España, vacaciones); recreativo-cultural; asociativo. J. Babiano y A. Fernández Asperilla constatan que las asociaciones que la componen (algunas como las de Bordeaux, Saint-Denis, Toulouse, Perpignan se remontan a las décadas de entreguerras) logran más adhesiones que los partidos y sindicatos. Sus manifestaciones culturales curiosamente llegan a parecerse a las de los exiliados. José Babiano recusa la idea de la anomia social y de la subordinación ilimitada de la FAEEF. Pero no cabe duda de que es a partir de 1975 cuando su ofensiva con respecto al retorno se hace más frontal.

3) Asociaciones de retornados. Existen asociaciones «transversales» sitas en España de emigrantes retornados, como "APOYAR», de sigla emblemática (asistencia pedagógica, orientación y apoyo al retorno). «Independiente, no lucrativa», se inició en Madrid en 1980. Su meta es la promoción cultural; cuenta ya con una revista "Apoyo-Info» para facilitar el acceso al mundo laboral y la reintegración en la sociedad española.

A escala autonómica es de citar, entre las más antiguas, la dinámica «AGER» (Asociación granadina de emigrantes retornados). Su presidente, Antonio Rojas Castro, pone de manifiesto que los retornados ya no mandan divisas, ahora las reciben por los derechos adquiridos, ingresando las mismas en España y predica para que se olvide el concepto de persona «asistida» y se instaure el concepto de persona «usuaria» ${ }^{15}$. Esta distinción es fundamental. Pues a lo que aspira hoy el retornado no es únicamente al respeto de sus derechos materiales sino a los inmateriales: al respeto a secas.

\section{LA PRESIÓN DIPLOMÁTICA AL SERVICIO DEL RETORNO}

Lo estamos viendo: el retorno - Historia de historias- es un «affaire d'État». Afecta no sólo al núcleo familiar sino a toda la nación, por eso un artículo de la Constitución española de 1931 y dos artículos de la Constitución de 1978 (art: 11 y 42) ${ }^{16}$ hacen hincapié en él. Para exponer brevemente las rela-

15 Sobre Apoyar y Ager: Cembrero Marcilla, J., López Vivanco, García Liébana, C. y Rojas CASTRO, A.: Politicas de retorno..., op. cit., pp. 251-275.

16 Artículo 42, BOE del 29 de diciembre 1978: «El Estado velará especialmente por la salvaguardia de los derechos económicos y sociales de los trabajadores españoles en el extranjero, y orientará su política hacia su retorno».

Hispania, LXII/2, núm. 211 (2002) 577-596 
ciones internacionales al respecto me apoyo en la investigación de Antonio Niño y Lorenzo Delgado pues ambos nos explican que, en lo tocante a la emigración económica masiva a Francia, la preocupación - preocupación bilateral- es casi secular. Resumo. Durante el siglo XX, la atención a los emigrantes se convirtió en un motivo de constantes roces sobre dos cuestiones fundamentales: la protección laboral y la atención de las necesidades escolares y culturales. España intenta evitar

«la pérdida de ciudadanos debida a la política sistemática francesa de aculturación 'uniforme' y naturalización (ius soli) del inmigrante para compensar sus crisis demográficas (muy diferente del sistema anglosajón de integración 'pluralista'); esta preocupación española arranca realmente con la Primera Guerra Mundial, nada más constituirse el 'Comité de Rapprochement franco-espagnol' y su homólogo español».

Reclamación clave: «'nos gustaría encontrar en su patria las mismas facilidades que encuentran en la nuestra las escuelas y colegios franceses'. 'Se trata de un tema muy importante para nosotros'». Las autoridades francesas tienen claro que la incultura es enemiga del retorno: «Es imposible que conserven mucho tiempo, en tan lamentables condiciones, sus lazos de unión con la patria». A las autoridades españolas tampoco se les escapa esta traba al regreso pero por falta de dotación presupuestaria sus intentos fracasan. La II ${ }^{\mathrm{a}}$ República agilizó el proceso ampliando el número de maestros en París, Toulouse, Burdeos, Sète, Perpignan, etc. El primer franquismo tuvo marginado el tema de la «re-españolización de los emigrantes afrancesados con escuelas genuinamente españolas» hasta el reconocimiento por Francia: la petición «sobre el papel» no pasó de ser un «tira y afloja» retórico-diplomático hasta la reapertura de la frontera en 1948. Y, comentan A. Niño y L. Delgado, hay que esperar el «boom» migratorio de los años 60 para que la presión diplomática tome realmente vigor y eficacia ${ }^{17}$.

\section{LA CRECIENTE IMPLICACIÓN DE LAS AUTONOMÍAS EN EL RETORNO}

Cancelada (o casi) la emigración laboral en 1973, las vueltas no son inmediatas; se vienen escalonando hasta hoy. Carecemos de verdaderas síntesis para estas tres últimas décadas del siglo pues los trabajos de J. Rubio y F. Parra Luna, sobre La emigración española en Francia, son de 1974 y 1981. Remito al estado de la cuestión presentado por G. Álvarez Silvar y A. Izquierdo Escri-

17 Delgado, L. y NiÑo, A.: «Emigración, enseñanza y nacionalidad en las relaciones hispanofrancesas», en España y Francia, en la paz y en la guerra: 1914-1945, Historia Contemporánea 10 (1993), Universidad del País Vasco, pp. 51-101. En pp. 51-52, frase de Rafael Altamira a Imbart de la Tour citada por L. Delgado y A. Niño, op. cit., p. 54, p. 60.

Hispania, LXII/2, núm. 211 (2002) 577-596 
bano18; aportaré pocas evaluaciones cuantitativas porque están fuera de mi alcance, y los datos dispares encajan difícilmente. El proyecto «Padrón Continuo" parece prometedor para el futuro. El retorno es difícil de medir porque es diferenciado: incide el modelo migratorio, individual o familiar; inciden las políticas de los países de acogida, unos países retienen más, otros menos. Durante el periodo 1961-1976, el $80 \%$ regresa de Alemania, contra el $60 \%$ de Francia; en Francia permanecen más tiempo que en Alemania o Suiza (donde sólo el $24 \%$ permanece más de 7 años ${ }^{19}$.

El hecho es que los promedios «aplastan» una realidad compleja y contrastada: en Francia, factores positivos y factores negativos, que van desde las mayores facilidades de reagrupamiento familiar y de naturalización hasta las menores posibilidades del ahorro, confluyen en la retención del emigrante. Por añadidura, contrariamente a lo que se podía pensar, la proximidad geográfica no garantiza el retorno pues al permitir el viaje frecuente, que es como un «regreso substitutivo», aplaza «el retorno de veras» ya que las visitas paliativas a la larga apuntalan la emigración.

Evidentemente, la aprensión a la vuelta es fuerte: el tiempo paulatinamente naturaliza, la adquisición de bienes raíces enraíza, la resistencia de los hijos retiene... La visión del futuro tan clara al salir ahora se turba. Son necesarios tantos reajustes: reajustes de los estudios, de las profesiones, de las jubilaciones, sin contar los reajustes domésticos o culturales. Sin embargo, con la jubilación, más de uno «se lo vuelve a pensar» por última vez ${ }^{20}$.

Desde los años 80 , las redes asociativas encauzan retornos, amortiguan rupturas y el gobierno democrático desarrolla una política cada vez más reacogedora, a la inversa de los años 60 en que favorecer los retornos hubiese supuesto una pérdida económica. Todavía en 1978 los programas electorales siguen interesándose más por el aporte económico (importante) que por la pretensión al retorno de los emigrantes. Incluso la democracia principiante, en un

18 Las fuentes estadísticas básicas de los estudios recientes son las bajas consulares del Registro Consular; las demandas de empleo del INEM; la serie «Migraciones» del INE: cfr. ARANDA AZNAR, J.: «Situación actual del retorno. Los motivos de cambio de residencia», en Políticas de retorno..., op. cit., pp. 15-28. IzQuierdo Escribano, A. y Álvarez Silvar, G.: «Estado...», Ibid., pp. $45-57$. PÉREZ LEIRA, L.: «El retorno: un fenómeno a debate», Ibíd., pp. 217-219. AZCÁRATE LUXÁN, B.: «El retorno de los emigrantes», en $A$ distancia, vol. 18, n 1 (junio 2000), pp. 217-225.

19 BABIANO, J. y Fernández ASPERIlla, A.: op. cit., pp. 16-17. 1985-1994: media anual de bajas consulares superior a 25.000. Ejemplo de disparidad: en Francia, en 1992, 435.039 españoles en régimen de matrícula consular; censados: la mitad. El Padrón continuo, más «al día» que los censos espaciados, será el equivalente del «Registro de población» que tienen ya varios países de la UE.

20 FERNÁNDEZ ASPERILla, A.: «iQue treinta años no es nada!...», en Situaciones de exclusión de los emigrantes españoles ancianos..., op. cit., p. 229, nota 52: «hay que hablar no de retorno forzoso sino más bien de permanencia forzada en los países de destino. Los emigrantes no vuelven por la dificultad para incorporarse al mercado de trabajo español o porque no han conseguido ahorros suficientes". Tampoco responden a los requisitos de las RMI y además en España no está asegurado el «riesgo de dependencia».

Hispania, LXII/2, núm. 211 (2002) 577-596 
primer momento, pondrá más interés en la preservación de la identidad en el extranjero que en la definición de una política de acogida del retornado. Son las autonomías las que, a la postre, van a tomar progresivamente en cuenta las aspiraciones a la vuelta «indolora». Bien se vio en las «Jornadas sobre Políticas de retorno de emigrantes», del 5 y 6 de diciembre de 1996, organizadas conjuntamente por la Dirección General de Trabajo y Migraciones, la Universidade da A Coruña, y la Secretaría Xeral para as Relacións coas Comunidades Galegas, que ha dado lugar a la publicación ya citada ${ }^{21}$. La calidad de la reinserción laboral ha estado en el centro de los debates. Se recuerda que, en 1980, el Servicio de Acción Social se dota con una Sección de Asistencia Social a Emigrantes, una Sección de Asistencia al Retornado y una Sección de Asistencia Educativa; Mauro Herrera Acosta (Jefe de Servicio de la Dirección General de Trabajo y Migraciones) muestra como a partir de ahí se institucionalizan las ayudas al retornado. En lo que se refiere a la Seguridad Social del retornado y de su familia, Carlos García de Cortázar y Nebreda (Subdirección General de Relaciones Sociales Internacionales) subraya el esfuerzo que ha realizado el Estado español dentro y fuera de sus fronteras mediante convenios internacionales, europeos o bilaterales y no vacila en decir que, a pesar de cierto aspecto asistemático, dicha acción es paradigmática. En cuanto a Margarita Melís Maynar $^{22}$ (Ministerio de Cultura) aboga por la homologación de títulos extranjeros en España y la agilización de las tramitaciones. A nivel autonómico, la «tercera edad» merece una atención especial, desde la ayuda socio-sanitaria hasta el simple viaje a España del emigrante y se han destacado primero por su labor las Juntas de Andalucía, Galicia, Extremadura y Castilla y León ${ }^{23}$. Está claro que la acción de las distintas comunidades se agudiza en los 90 .

\section{EL RETORNO DEL VOTO. UNA CAMPAÑA DE PRENSA}

A partir de la segunda mitad de los años 90, los partidos políticos se interesan cada vez más por la población emigrada y su atención algo tiene que ver con la voluntad de granjearse votos en vísperas de elecciones. Un indicio de ello lo da, en el primer trimestre de 1999, la página semanal de El País internacional titulada «El mundo de la emigración»; aquí sólo se indican unas directrices a guisa de botón de muestra, pero sería preciso, claro está, extender el vaciado a otras crónicas dirigidas a la emigración.

\footnotetext{
21 IZQUiERDo EsCRIBANO, A. y ÁlVAREZ Silvar, G.: op. cit.

22 GARCÍA DE CORTÁZAR Y NEBREDA, C.: «La seguridad social del retornado y su familia », en Políticas de retorno..., op. cit., pp. 149-157. MELís MAYNAR, M.: «Reconocimiento de títulos extranjeros en España", Ibíd., pp. 81-93.

23 Herrera ACOSTA, M.: «Inserción socio-laboral del emigrante retornado», en Políticas de retorno..., op. cit., pp. 95-147. Gálvez Arjona, M., Domínguez, J., Amarelo De CaStro, F. y García-PRiETo, J.: Ibíd., pp. 185-208.
}

Hispania, LXII/2, núm. 211 (2002) 577-596 
Durante los meses y semanas que preceden las elecciones, todos los partidos políticos multiplican sus encuentros con los emigrantes y es sintomática la mediatización periodística entre diciembre de 1998 y junio de 1999, siendo la fecha de los comicios el 13 de junio. Y, digámoslo de antemano; para un resultado global aparentemente decepcionante, por lo que puede leerse en el balance de principios de julio (6-12), bajo el titular y la entradilla siguientes:

«Escasa participación de los emigrantes en los comicios del 13 de junio: Mercedes Herranz Carmen Cerdeira responsable de emigración del Partido Socialista Obrero Español (PSOE) destacó la escasa participación de los emigrantes —el 15 $\%$ - en las elecciones europeas y autonómicas (no existen datos sobre las municipales)».

En la crónica, llama la atención lo proteico del enfoque: las diferentes generaciones de emigrantes, los «retornables» y los retornados, los diferentes países de acogida (los que conceden la doble nacionalidad y los que no; los europeos y los demás, etc.). Incluso la simple pregunta: ¿a quién se le considera retornado con derechos? puede tener varias respuestas según las zonas; así, para la Junta andaluza, acceder a las ayudas «para gastos extraordinarios derivados del retorno" requiere "haber residido fuera de Andalucía al menos tres años continuados y no haber transcurrido más de tres desde su regreso»; al parecer cada autonomía matiza sus ayudas y sus requisitos.

Los candidatos al retorno, sobre todo los procedentes de países no europeos, lamentan la falta de información sobre el poder adquisitivo, la vivienda, el tiempo mínimo de cotización para cobrar una pensión, etc. La confusión y la espera parecen tales que el director general de la DGOM, Juan Aycart, anuncia solemnemente la salida de la nueva Guía del retorno: la Guía contendrá, además de la información general de retorno, varios temas importantes como el Real Decreto de pensiones asistenciales, la reforma de la legislación periférica e información sobre los países con los que España tiene convenios de Seguridad Social. La coherencia de la política migratoria nacional e internacional es reivindicada por las instituciones, enfatizada por los políticos, cuestionada por los emigrantes-electores quienes llegan a pedir la creación de una Secretaría de Estado para las Migraciones que «calibre necesidades y unifique respuestas».

También en el ámbito cultural se aspira a una planificación de la salvaguardia de «las señas de identidad». De paso se echa de ver que esa conservación de la cultura propia interesa al país receptor por ser una garantía de la vuelta del emigrante a su patria pues su estancia se considera temporal; no es de extrañar que Lionel Jospin conceda en 1999 la medalla de Caballero de la Orden Nacional del Mérito a Juana Gómez, autora, precisamente, de una Guía de Recursos Culturales Españoles en Francia, por su labor en Marsella.

Una de las condiciones para favorecer debidamente la re-integración de los retornados es facilitar la integración laboral sin que se produzca un desfase profesional lesivo. Por una parte se aboga por la convalidación de los diplomas, 
siendo el ideal perseguido la armonización de la legislación comunitaria con reconocimiento de títulos (o acuerdos bilaterales fuera de la UE). Por otra parte, se valora la titulación propia por la actividad de la UNED en el exterior, con sus 11 centros de apoyo, sus 1.500 alumnos, sus 18 titulaciones universitarias (sin contar el aporte de los Institutos Cervantes).

Además de las líneas culturales, «El mundo de la emigración» de 1999 anuncia líneas presupuestarias asistenciales como las dedicadas al retorno de las familias monoparentales (una prioridad), a los cursos de formación, a las plazas de residencias de ancianos, a las pensiones «no por debajo del salario mínimo profesional». Son abordadas incluso las dificultades psicológicas inducidas por el «volver a empezar», y se toma buena nota de la petición de una ayuda psicológica al emigrante retornado.

Todos, candidatos y electores, ostentan la misma voluntad de abarcar en su globalidad los problemas del retorno. Se es consciente que impulsar el retorno no basta y que se ha de adecuar la política para evitar la re-emigración: " conseguir una integración lo más correcta posible y evitar una segunda emigración, que muchas veces se produce cuando regresan al país». Tal vez de ahí venga la insistencia en el protagonismo reciente de las asociaciones de retornados. Se pueden leer declaraciones como éstas: «en Andalucía se ha pasado de tener una asociación hace tres años a las actuales seis, la última creada es la de 'Mujeres progresistas'»; «es preciso crear una asociación de retornados con sede en Madrid», etc.

Se nota en esos meses preelectorales una aceleración en los programas y compromisos: se afirma que «hay que actuar urgentemente en el tema del retorno que se está produciendo de forma más masiva de lo previsto", se recuerdan avances, se anuncian mejoras, pero no cabe duda de que el discurso se dirige, a través del emigrante, al elector, pues se comenta «la importancia que tiene el voto de los emigrantes en el resultado electoral». Se dan cifras: 887.857 emigrantes españoles podrán ejercer su derecho de voto. Queda claro que una de las preocupaciones del político es el censo electoral. Y se recalca: cabe «ampliar el Censo de Residentes Ausentes» evaluado en dos millones; cabe «mejorar la inscripción en el censo electoral».

Por fin, bien sabe el político que para calar hondo ha de valorar a su interlocutor o a su lector: no sólo con medidas asistenciales se puede conquistar a un electorado. Sería contraproducente identificar al emigrante con un asistido. El emigrante aporta ${ }^{24}$ (divisas, personalidad, cultura): se aspira pues a que esté «presente en la vida política».

24 Matizan dicho aporte: GARSON, J. P., TAPINOS, G. P. et alii.: "L'argent des immigrés, revenus, épargne et transferts de huit nationalités immigrées en France», en Travaux et Documents, $\mathrm{n}^{\circ}$. 94, Paris, PUF, INED, 1981: transferencia de los ahorros por año y por persona activa: portugueses 18.932 F, españoles $14.442 \mathrm{~F}$, sin contar el aporte sumergido; L'Avenir des migrations, OCDE, 1983: los inmigrados no participan en el desarrollo económico de su zona por su débil calificación y por el tipo de inversión que eligen. AzCÁRATE LuXÁN, B. (op. cit.., p. 215): «el volumen de las divisas no 
(N.B. En el verano de 1999, cesó la publicación del País Internacional, un semanal con miras al hispanismo exterior y a la emigración al que suscribían la mayoría de los centros docentes en los que se enseña el español (colegios, institutos y universidades). ¿Puede sustituirlo El País digital?)

\section{LA LITERATURA: UN DEPÓSITO DE LAS SEÑAS DE IDENTIDAD}

Después de todo lo dicho, era lógico pensar que una emigración de tal envergadura y tales implicaciones humanas había dejado una huella en la creación cultural y despertado el interés de la crítica. La película El Emigrante, de Sebastián Almeida, 1959, o la novela Diario de un emigrante, de Miguel Delibes, 1958, inauguraban el periodo. Pero hay que rendirse ante la evidencia: o la producción es poca durante estos últimos veinte años o son poquísimos los críticos y universitarios que han investigado la emigración económica española bajo el ángulo de la "creación» ${ }^{25}$. Al parecer tampoco es atendido este campo de investigación en países tradicionales de emigración como son Portugal, Italia o Irlanda. Hay indicios de que «un día se prestará atención al fenómeno literario de la emigración». Para remediar en algo esa laguna, la Fundación $1^{\circ}$ de Mayo - con su Centro de Documentación de la Emigración Española - ha incluido entre sus proyectos un trabajo de investigación sobre la creación literaria en el entorno de los emigrantes españoles en Europa, considerando que la literatura es una fuente importante a partir de la que se puede reconstruir la experiencia histórica. Acaba de publicar Emigración española y creación literaria. Estudio introductorio (1999), obra de José Rodríguez Richart, quien hace un recorrido por los autores de la España del interior y del exterior que han tocado el fenómeno de la emigración laboral.

Hay antecedentes, pero todos relacionados con la emigración a América: véase el recuento de obras sobre La emigración asturiana a América por Antonio Martínez Cachero (A. Camín, L. Aurelio, C. Villar Loza, A. Martínez Cuétara, Á. Pola, e incluso el Leopoldo Alas de Boroña); y la vertiente gallega desde R. de Castro hasta A. R. Castelao. Para el periodo que nos ocupa, son de señalar la novela del gallego Daniel Sueiro: El regreso de Frank Loureiro (1964) o, más reciente aún, la del escritor cubano Miguel Barnet, Gallego (1981). En poesía un ejemplo magistral lo da el poema «Réquiem» de José Hierro. Se podría seguir la pista "americana» sin demasiada dificultad. Eso pone aún más de relieve lo escaso de la cosecha «europea».

ayudó a crear puestos de trabajo para los emigrantes, ni contribuyó al desarrollo económico y social de las regiones de origen, con lo que las estructuras sociales y económicas siguieron siendo las mismas, sino que tales divisas se invirtieron preferentemente en proyectos de infraestructura dirigidos fundamentalmente a los grandes centros económicos del país».

25 RODRíGUEZ RICHART, J.: Emigración española y creación literaria. Estudio introductorio, Madrid, Fundación $1^{\circ}$ de mayo, Centro de Documentación de la Emigración Española, 1999. 
La utilísima recensión europea de José Rodríguez Richart, desde dos observatorios -el del emigrante implicado y el del observador exterior- concierne tres países esencialmente: Alemania, Bélgica, Francia. El tema del retorno de Alemania ha merecido la atención de Francisco Ayala en su novela breve $E l$ rapto (1974). También el escritor albaceteño Rodrigo Rubio sitúa en Alemania su historia de un joven emigrante muerto en un hospital de Dusseldorf, Equipaje de amor para la tierra (Premio Planeta, 1965). Ángel María de Lera es autor de un libro de reportajes, Con la maleta al hombro (1965), y de dos novelas, Hemos perdido el sol (1963), Tierra para morir (1964). Otros narradores cuentan su experiencia directa de la emigración alemana: son Víctor Canicio, Patricio Chamizo o Torcuato Miguel. Cabe citar a José Martín Artajo, cónsul de España en Frankfurt, en donde empezó a escribir la Historia de la misteriosa desaparición de Porfiria Santillana, fregona española en país superdesarrollado, publicada en Méjico en 1970, así como la obra de la escritora Mercedes Neuschäfer-Carlón, $A n$ tonio en el país del silencio (1991), que adopta la perspectiva de un niño. J. Rodríguez Richart señala las obras teatrales de Vicente Ballester Gil, trabajador valenciano, y los sainetes del obrero malagueño Manuel Sellés. Heleno Saña, poeta y ensayista barcelonés afincado en Darmstadt, ha reflejado la emigración en obras de contenido biográfico como Una guerra sostengo, Viajero en la tierra, Crónica de una ausencia y alguna más. Otro caso singular es el de Domènec Canet, emigrado temporalmente a Alemania, que obtuvo en 1970 el premio de poesía «Ausiàs March» del Ayuntamiento de Gandía por Des del meu exili voluntari.

La escritora española Dolores Soler Espiauba, residente en Bélgica, centra sus novelas en los españoles «retornables»: Los canardos, Doce rosas para Rosa (1989), Hermana Ana iqué ves? (1990), Elisa o el pasado imperfecto (1992), El oro y el moro (1994). Abunda la poesía del retorno. Son de citar tres antologías (Bélgica y Alemania esencialmente): Antología poética de la emigración (1981); Poesía castellana en Bélgica (1983-1984); Huérfanos de sol en estas tierras (1989) compuesta de poemas publicados en el semanario 7 Fechas, entre los años 1974 y 1978, y escritos en su mayoría por residentes en Alemania (dos en Francia).

Pasemos a Francia. Diré sin ambages que, comparada con la «americana»o la «alemana», la «literatura emigrante» recopilada en Francia decepciona. ¿Señal de una integración más suave? ¿Nivel cultural más bajo? Pero tal vez, sencillamente, el trabajo de recopilación sistemático quede por hacer, como lo deja suponer la reciente edición-exhumación por Frédéric Serralta de Don Juan Tenerio el "Refugiao», de Juan Mateu, el albañil de Toulouse ya mencionado. O tal vez empiece ahora el tiempo de la escritura diferida y de la memoria. La recolección de José Rodríguez Richart, pues, — «del vaudeville al dramón», resulta escuetísima... Miguel Mihura ha tratado, de forma indirecta y superficial, el tema de la emigración española a Francia en Ninette y un señor de Murcia (1964) y Ninette, modas de París (1966). Merece mayor atención, para el tema, Años de ceniza, obra teatral de Lorenzo F. Carranza, finalista del Premio Lope de Vega 
de 1978. La obra plantea en términos sombríos los problemas existenciales básicos —sociales, familiares, generacionales- que conlleva la emigración. El drama es el cruel enfrentamiento de los hijos con los padres cuando éstos deciden volver; el telón de fondo es de enfermedad y tristeza ${ }^{26}$.

\section{UNA TRABA AL RETORNO: ¿LA «ACULTURACIÓN» O LA «CONTRA-ACULTU- RACIÓN»?}

Uno de los rasgos más llamativos de todos estos escritos, traten de la emigración a Alemania o a Francia, es que siempre describen a un grupo en trance de retorno. Este estar en estado permanente de vuelta explicaría, según las encuestas directas de Guy Hermet - que resultaron pioneras en los años 60-, la pobreza de las actividades culturales (que raramente pasa de la escucha de las variétés radiofónicas). La ausencia de asimilación cultural del emigrante español en Francia - su «contra - aculturación»- sería debida, primero, al retorno del ahorro excesivo y, después, al retorno del emigrante, un emigrante por tanto indiferente al entorno, a sus modelos, a su lengua. El comentario es éste:

«[L'attachement à l'Espagne] et le désir de retour au pays exerce dans certains cas une action retardataire en matière culturelle. En effet, ces phénomènes n'ont pas seulement pour conséquence de provoquer une épargne ou des envois d'argent disproportionnés par rapport aux ressources disponibles. Ils conduisent aussi les Espagnols qui souhaitent rentrer chez eux au plus tôt, ou qui hésitent à rester longtemps en France, à ne pas entreprendre sérieusement l'étude de la langue française. Cet attachement au pays d'origine entretient souvent une indifférence paresseuse ou hostile à l'égard des modèles offerts par le pays d'accueil et déclenche même parfois un véritable processus de contre-acculturation» ${ }^{27}$.

El elemento cultural, Guy Hermet lo examina a través de dos prismas, la iglesia y la escuela. Compara el comportamiento de los exiliados y el de los emigrantes frente a esas dos instituciones. La frecuentación de la iglesia es prácticamente nula en los republicanos, y activa en los emigrantes recientes para decaer bastante al cabo de cinco años:

26 Ibid., pp. 14-15.

27 HeRmET, G.: op. cit., pp. 140-141; F. Dubet habla de «ausencia de identificación ", op. cit., p. 113: "Certaines anciennes immigrations sont caratérisées par une forte intégration, une forte assimilation aussi et, de manière paradoxale, par une faible identification nationale avec la France. C'est la situation que suggèrent les retours d'Espagnols et de Portugais à l'heure de la retraite, et les faibles participations aux élections locales ouvertes aux étrangers». Ejemplo: TAOBADA LEONETTI, I. y GUILLON, M.: Les immigrés des beaux quartiers. La communauté espagnole de XVIe arrondissement, Paris, CIEMI, L'Harmattan, 1987: el $92 \%$ de las personas entrevistadas quiere volver al país. 
«Les réfugiés ne vont pratiquement jamais à l'église, alors que les Espagnols immigrés pour des raisons économiques ou personnelles conservent pour la plupart un minimum de pratique. [...] Des différences semblables se manifestent entre les personnes qui ont quitté l'Espagne depuis plus de cinq ans et les immigrants récents, qui assistent beaucoup plus souvent que les premiers à des cérémonies religieuses» ${ }^{28}$.

Mediante un sondeo - que, insisto, se sitúa en pleno franquismo- se adentra en la comparación entre emigrantes oriundos de diversas provincias, estableciendo diferencias en la actitud frente a la iglesia entre rurales y urbanos, entre las gentes de Cataluña, Aragón, Levante y los habitantes de otras zonas:

«Dans une moindre mesure, le milieu et la région d'origine constituent aussi des facteurs susceptibles d'influer sur la fréquentation religieuse. Des différences statistiques significatives séparent, en effet, le comportement des ruraux, des méridionaux, des Castillans et des personnes provenant de la zone Nord-Atlantique, qui vont assez souvent à l'église, de celui des immigrants originaires de la Catalogne, de l'Aragon, du Levant, ou de milieux urbains, qui s'y rendent moins fréquemment».

La actitud ante la escolaridad también difiere: los hijos de los emigrantes de los primeros años 60 salen a los 16 años del sistema escolar francés con el CAP («certificat d'aptitudes professionnelles»). Unos pocos van más allá:

«Les parents de ceux qui parviennent à entamer des études secondaires ou supérieures appartiennent tous, à une exception près, à la petite 'élite intellectuelle' qưi s'est manifestée à propos de la fréquentation des bibliothèques, ou de l'assistance aux réunions et conférences».

La visión era bastante pesimista para el futuro y en eso Guy Hermet erraba ya que los hijos de los inmigrados quedaron atrapados irresistiblemente en la «masificación» francesa de los estudios secundarios de los 70 y la de los estudios universitarios de los 80 . Y es sabido que los estudios de los hijos entorpecen el retorno de los padres... ${ }^{29}$

Pero, paralelamente, la no-renovación del flujo inmigratorio se lee, irrefutable, en la década de los ochenta, en las estadísticas escolares. Un ejemplo: ya, en 1981-82, los alumnos españoles de «Second Degré» (la enseñanza de «Segundo grado» viene a continuación de la «Básica») con un total de 29.349 sólo representan el 9,8 \% del alumnado extranjero, los portugueses el 23,9\%; 1982-83: 28.078 (8,9 \%; portugueses $22 \%)$; 1983-84: 26.300 (7,9\%; por-

\footnotetext{
28 Ibíd., p. 156.

29 WeIL, P.: La France et ses étrangers. L'aventure d'une politique de 1938 à nos jours ( $1^{\mathrm{a}} \mathrm{ed}$. Calmann-Lévy, 1991), Paris, Gallimard 1995, p. 387.
} 
tugueses $23,8 \%$ ); a los siete años la presencia española en los Lycées se ha quedado en la mitad: $1989-90,14.129^{30}$.

A guisa de conclusión añadiré un par de reflexiones más. La primera sería que es difícil medir con el mismo rasero tantos retornos distintos; todo varía: el espacio, el tiempo, la circunstancia, la rentabilidad de las distintas "campañas», la aculturación, etc. La segunda es que estamos confrontados con la cuestión de la «historia del tiempo presente», y su visión dinámica articulada con los problemas que son los nuestros, su función crítica en la sociedad de hoy. En efecto, el retorno de aquellos emigrantes españoles que se fueron a los países industrializados de Europa, entre 1956 y 1973, es hoy una realidad comprobable. Muchos emigrantes se encuentran ahora mismo en un proceso de reintegración y las instancias de gobierno centrales y periféricas los observan con atención y siguen afinando políticas de retorno para allanar las dificultades de la reinserción en la propia tierra sin negar la aportación de la otra tierra. Hasta se podría decir que más que objeto de historia del tiempo presente es objeto de «historia del pasado-presente», para retomar el concepto de Gérard Noiriel ${ }^{31}$, gran especialista de la inmigración en Francia. El fenómeno del retorno es tanto más interesante de observar cuanto que España está en una situación diametralmente opuesta a la que originó la salida en masa hacia los países industrializados de hace unas décadas: demográficamente ya no es expulsora sino receptora. Es esclarecedor remontarse del presente al pasado. El movimiento migratorio

\footnotetext{
30 La note d'information (anual), MEN, Direction de l'Évaluation et de la Prospective. Más datos: 1985-86: 23.223; 1986-87: 20.817; 1987-88: 17.775; 1988-89: 16.276. Sobre educación, en zonas de emigración de gran magnitud, como puede serlo Galicia por ejemplo, habría que estudiar ciertas «quiebras»: el caso de las parejas emigradas que tenían hijos que dejaban en España al cuidado de sus abuelos o de sus tíos y acabaron convirtiéndose en desconocidos para sus padres y los que tenían en el exterior y vivían con ellos y acabaron siendo sus «verdaderos hijos»; el caso de los hijos que sólo eran reclamados por sus padres cuando alcazaban la edad laboral, en tanto que sus hermanos «extranjeros» estudiaban el bachillerato e incluso iban a la Universidad (otra "variante»: la de los emigrados que enviaban a sus hijos de España a internados y ahí los dejaban durante las vacaciones); el caso de los hijos que repudiaron a sus padres y consiguieron por vía judicial que la patria potestad recayese en sus tutores temporales. Hubo varias quiebras de este estilo. No aparecen en estudios sobre el tema porque desentonan con la imagen de los emigrantes sacrificados por su familia. No se ha hecho una reflexión seria sobre las quiebras sociales que la emigración ha causado. Enfoque inverso, cfr. HOUTART, F., KASANDA, A. y COMPÈRE, J.: «Los inmigrantes españoles de la tercera edad en Bélgica», en Situaciones de exclusión de los emigrantes españoles ancianos..., op cit, p 154: «Cuando el niño llegaba de la escuela, estaba solo en casa; la mamá no estaba, se había ido a limpiar oficinas; entonces el pequeño se quedaba solo en casa; o bien se iba a la calle, veía a sus amigos [...]; tuvieron muchos problemas'. Los valores trabajo y dinero iban por delante de la educación».

31 NoIrIeL, G.: Le Creuset français. Histoire de l'immigration, XIX-XXe siècles, Paris, Seuil, 1988; Sur la crise de l'bistoire, Paris, Belin, 1996; Qu'est-ce que l'bistoire contemporaine?, Paris, Hachette, 1999.
} 
que ocupa ahora el primer plano del escenario político y de la prensa escrita, televisiva o digital no es la migración de retorno española sino la reciente inmigración extranjera. El retorno de aquella caduca emigración se involucra en una coyuntura social en que el problema candente ya no lo constituye la emigración sino la aparición de una inmigración más o menos controlable. Esta España atractiva está desarrollando una política migratoria en relación con la configuración social de la Europa actual, una política en la que entran los retornados y los inmigrados. Esto finalmente la obliga a avanzar a marchas forzadas para atender a unos sin desatender a los otros. 